\title{
BELIEVING IN PERCEIVING: KNOWN ILLUSIONS AND THE CLASSICAL DUAL-COMPONENT THEORY
}

\author{
Jake Quilty-Dunn \\ Philosophy and Cognitive Science, CUNY Graduate Center \\ Forthcoming in Pacific Philosophical Quarterly, \\ Special issue "The Disunity of Perception," edited by Indrek Reiland and Jack Lyons
}

\begin{abstract}
According to a classic but nowadays discarded philosophical theory, perceptual experience is a complex of nonconceptual sensory states and full-blown propositional beliefs (Reid 1764/1997, 1785/2000). This classical dual-component theory (Smith 2002) of experience is often taken to be obsolete. In particular, there seem to be cases in which perceptual experience and belief conflict: cases of known illusions, wherein subjects have beliefs contrary to the contents of their experiences. Modern dual-component theories reject the belief requirement and instead hold that perceptual experience is a complex of nonconceptual sensory states and some other sort of conceptual state. The most popular modern dual-component theory appeals to sui generis propositional attitudes called "perceptual seemings" (e.g., Tucker 2010, Brogaard 2014, Reiland 2014). This paper argues that the classical dual-component theory has the resources to explain known illusions without giving up the claim that the conceptual components of experience are beliefs. The classical dual-component view, though often viewed as outdated and implausible, should be regarded as a serious contender in contemporary debates about the nature of perceptual experience.
\end{abstract}


"Perception commands our belief upon its own authority, and disdains to rest its authority upon any reasoning whatsoever."

—Reid 1785/2000, 99

\section{$\$ 1$-Introduction}

There is a mass grave of classic philosophical theories that are historically important, philosophically interesting, and worth studying, but are presumed dead from the perspective of contemporary theorizing. One such view, which may yet have a pulse, is that perceptual experiences are complexes of nonconceptual sensory states and beliefs. ${ }^{1}$ This classical "dualcomponent view" (Smith 2002, 67) is typically associated with Reid (1764/1997, $1785 / 2000$ ), and is widely considered to be false. There have been many objections raised to the classical Reidian dual-component theory (see Smith 2002), but perhaps the one that has carried the most weight is the problem of known illusions. In cases of known illusions, things perceptually appear one way while we occurrently believe that they are not that way. One such illusion is the Ames Room (Fig. 1). When initially seeing figure 1, you may be compelled to believe that the woman on the right is nearly twice as tall as the man on the left. But upon learning that the image is an Ames Room illusion, and that in fact the man is just farther away, you acquire the belief that it is not actually the case that the woman is nearly twice as large. Nonetheless, the perceptual appearance persists. Such cases also arise when the subject knows she is hallucinating or dreaming. So, the reasoning goes, the classical dualcomponent theory is mistaken in taking beliefs to be constituents of such perceptual appearances.

\footnotetext{
${ }^{1}$ Throughout, I will often use the term 'perceptual experience', which standardly denotes conscious perception. The paper is intended to be neutral on what separates perceptual experience from unconscious perceptual states. What follows should, furthermore, be compatible both with the claim that unconscious representational contents are always distinct in type from conscious contents (see, e.g., Burge 2014, 491), and with the claim that any type of mental state that occurs consciously could also occur unconsciously (e.g., Carruthers 1996, 135). The primary focus, however, will be conscious perceptual awareness, i.e., perceptual experience.
} 


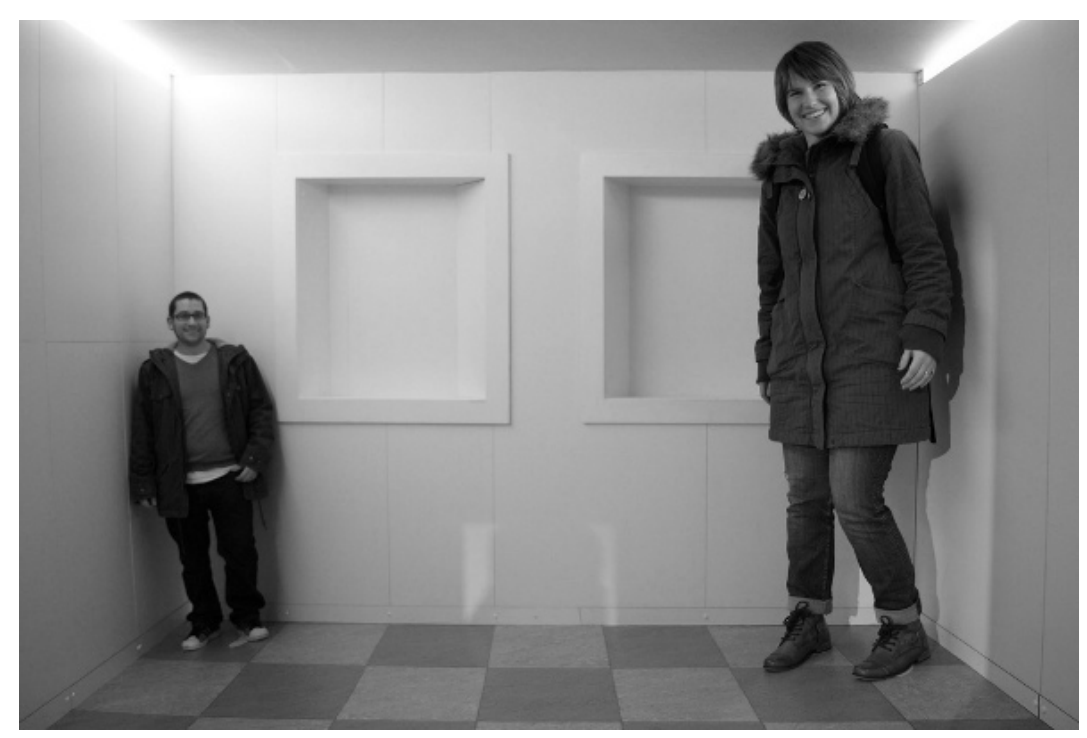

Figure 1-Ames Room illusion ${ }^{2}$

The dual-component theory has been revived, however, in a way designed (inter alia) to avoid the problem of known illusions. There are, after all, many theoretical and normative benefits to taking experience to involve both conceptual and nonconceptual aspects (see, e.g., Sellars 1956, Peacocke 1992, Coates 2007). On what I'll call modern dual-component theories, the conceptual components of experience are not beliefs but some sui generis type of propositional attitude. The dominant form of modern dual-component theories in recent years appeals to perceptual seemings (Tucker 2010, Brogaard 2014, Reiland 2014). Brogaard writes that "visual seemings clearly are not belief states. You can believe that $p$ even if it visually seems to you that not-p" $(2014,383)$. Thus modern dual-component theorists posit a distinct propositional attitude that performs a similar function to belief on the classical dual-component view. ${ }^{3}$

\footnotetext{
2 "Ames Room" by Ian Stannard, taken from https://www.flickr.com/photos/silly_little_man/5132242358 on 9 August 2015 and altered to grayscale and size reduced. Licensed under Creative Commons License Attribution ShareAlike 2.0 Generic: https://creativecommons.org/licenses/by-sa/2.0/

${ }^{3}$ In addition to holding that the conceptual components of experience are beliefs, Reid also held that the sensory components by themselves don't make us aware of external objects (e.g., $1785 / 2002,36$ ). This thesis is orthogonal to the disagreement between the classical and modern views as understood here. The response offered below to the problem of known illusions on behalf of the classical dual-component theory is neutral on whether sensory states represent, or perceptually relate us to, external objects. The Reidian version of the classical view may fail to withstand scrutiny for independent reasons having to do with the nature of sensory representation unexplored here.
} 
My primary focus will be the classical dual-component view, which I believe has not been given its due. I'll argue that the classical view has the resources to reply to the problem of known illusions without adverting to perceptual seemings. In particular, I'll argue that perceptual beliefs on the classical theory should be formed automatically and may persist despite not being endorsed by the perceiving subject, and that this view is still substantively different from modern dual-component theories. In $\$ 2$, I will attempt to get clearer on what accepting a dual-component view amounts to, outlining more modest and more ambitious versions. In $\$ 3$, I will discuss the problem of known illusions, how the classical view may respond, and how the classical view thus construed differs in substantive ways from modern views. In $\$ 4$, I will conclude. While there may be good reasons to favor modern over classical dual-component views, the problem of known illusions isn't one of them.

\section{$\$ 2$ - Spelling out the view}

There is a very modest relative of the dual-component view that is somewhat popular in contemporary philosophy, which is captured in (1):

(1) $S$ perceptually experiences a as $F$ only if $S$ is in a state (or complex of states) that exhibits both nonconceptual sensory aspects ${ }^{4}$ and conceptual content representing a as F. ${ }^{5}$

${ }^{4}$ I employ the phrase 'nonconceptual sensory aspects' to remain neutral on whether these aspects are constituted by nonconceptual representational contents (Tye 1995, Peacocke 2001), nonrepresentational, purely qualitative features (Reid 1764/1997, 1785/2000), or relations to objects or properties (Bengson et al. 2011). I will discuss the distinction more fully below. If the nonconceptual element is best understood as exhibiting representational content, what follows should nonetheless be neutral, unless otherwise indicated, on whether the "state" or "content" construal of nonconceptual content is preferable (Heck 2000, Byrne 2005).

${ }^{5}$ Note that this is an only-if-statement rather than an iff-statement; these are meant only to be necessary conditions, not sufficient. Biconditionals are generally very difficult to formulate accurately, as much of twentieth-century Anglophone philosophy shows. There are, additionally, many worries about the sufficient conditions for perceptual experience-e.g., proper causation (Chisholm 1957, Grice 1961, Searle 1983, McLaughlin 1984, Coates 2007), relation to consciousness (Chalmers 2004, 2006), and past relations to the environment (Tye 1995, Burge 2010)— that would best be left aside for now. Furthermore, it will be useful to be able to refine and reformulate the view as we go, and only-if statements better facilitate that sort of gradual refinement.

The formulations that follow will take experiencing-as as primary, rather than some more primitive notion of experiencing tout court. Given that all dual-component theorists are 
According to (1), perceptual experience involves conceptual content as well as a nonconceptual component, which may or may not be contentful. Theorists who seem committed to (1) include Reid (1764/1997, 1785/2000), Sellars (1956), Evans (1982), Peacocke (1992, 2001), Pylyshyn (1999), Lyons (2005), Rosenthal (2005, 2010), Coates (2007), Fodor (2007), Tucker (2010), Bengson et al. (2011), Reiland (2014, forthcoming), and Brogaard (2014). Those who reject it include Dretske (1969, 2000), McDowell (1994), Tye (1995), Smith (2001, 2002), Hopp (2011), Gupta (2012), and Mandik (2012). Though (1) is a kind of dual-component view, and is certainly controversial, I will try to defend a more restrictive, ambitious, and controversial dual-component view. One example of a more restrictive thesis is (2):

(2) $S$ perceptually experiences a as $F$ only if $S$ is in a propositionally structured state that represents a as $\mathrm{F}$ and that state either exhibits or is accompanied by a state that exhibits nonconceptual sensory aspects.

Certainly Reid and Sellars endorse (2), as do many Sellarsians, such as Coates (2007) and Rosenthal (2005); Fodor (2007), Tucker (2010), Lyons (2005), Brogaard (2014) and Reiland (2014) likely do as well. One important terminological caveat, however, is that I use the term 'perceptual experience' to refer to the complex of nonconceptual and conceptual elements that the dual-component theorist posits. I do not mean to imply that no dual-component theorist can allow for seeing a as F to occur nonconceptually (see, e.g., Reiland forthcoming). However, all dual-component theorists have in common the claim that, at least for some Fs, nonconceptual and conceptual elements are required for some form of perceptual awareness of a as F, and it is that form of awareness that I refer to as "perceptual experience" or simply "experience."

Dual-component theorists can, of course, disagree on how much they build into each component and what exactly the conceptual component is required for. One could argue that the conceptual component is only necessary for categorization and presentation of highlevel kind properties (in which case the relevant $\mathrm{F}$ should be assumed to be such a property), or that it is necessary to fulfill an evidential or justificatory role (Tucker 2010), or that it is necessary for perceptual representational content tout court (Bengson et al. 2011). I will leave these questions as open as possible, and use the term 'perceptual experience' to refer to whatever form of perceiving-as constitutively involves both components. Finally, the use of 'perceptual experience' shouldn't be taken to exclude the possibility that one can have

committed to some element of experience being conceptual, and given that conceptual representations arguably represent things as having features (Fodor 2007), the focus on experiencing-as seems appropriate (cf. Burge 2009, 249ff). 
conscious perceptual awareness of objects without conceptualization (Reiland forthcoming) - it's simply the term I'm using to pick out whatever all dual-component theorists agree requires both components.

(2) is highly controversial, but leaves it open what kind of propositionally structured state figures in perceptual experience. ${ }^{6}$ An even more restrictive and controversial thesis is (3):

(3) $S$ perceptually experiences a as $F$ only if $S$ forms the perceptual belief that a is $F$ and that perceptual belief either exhibits or is accompanied by a state that exhibits nonconceptual sensory aspects.

(3), unlike (2), restricts the relevant propositionally structured state to the domain of belief; (3) rules out any sui generis perceptual attitude figuring in the relevant propositional representation.

I use the term 'belief' to refer to a type of occurrent, representational mental state with a distinctive cluster of features: (i) propositional content, (ii) assertoric force or attitude (i.e., mentally affirming in a way analogous to the assertoric force of linguistic assertion), (iii) the capacity to serve as a mental premise in inferences, (iv) linguistic expressibility in creatures capable of linguistic expression, (v) being characteristically linguistically expressed in the form of an assertion, and (vi) being disposed to interact in characteristic ways with desires, emotions, action, and memory. ${ }^{7}$ One might instead use the term 'judgment' or 'thought' (e.g., Rosenthal 2005). ${ }^{8}$

${ }^{6}$ For Reid, such a state is simply a belief; according to Gupta (2012), Sellars rejected the doxastic view and instead took such propositional states to be a sui generis propositional attitude, "perceptual taking."

${ }^{7}$ Note that (iii), (iv), (v), and (vi) are dispositional features; a particular belief may be inferentially inert or isolated from linguistic expression, action, emotion, etc., for contingent reasons (e.g., cases of delusion, cognitive dissonance, Freudian repression, aphasia) without thereby failing to be a belief (Byrne 2009, Mandelbaum 2014). This point will come into play in the discussion of known illusions below. Moreover, (iv) and (v) are not meant to bar the attribution of beliefs to nonlinguistic creatures such as animals or infants. All that is meant is that such creatures, if they gained linguistic capacities, would be able to express their beliefs as assertions - though, admittedly, I'm not sure how to cash out that counterfactual claim. Finally, the characteristic interactions I have in mind in (vi) include, for example, such belief-desire truisms as, If $S$ believes that if $\mathrm{p}$ then $\mathrm{q}$ and desires that $\mathrm{q}$, then $S$ will act in such ways as to bring it about that $\mathrm{p}$.

${ }^{8}$ Some philosophers think that belief and judgment are different mental kinds (e.g., Lycan 1986, Schwitzgebel 2010, Mandelbaum 2014). I assume (and they seemingly deny) that 
It is unclear who, besides Reid, holds (3). In fact, the version of (3) that Reid held is yet more restrictive:

(3') S perceptually experiences a as $\mathrm{F}$ only if $\mathrm{S}$ tokens a nonconceptual sensory state which appropriately causes ${ }^{9}$ a perceptual belief that a is $\mathrm{F}$.

(3') is the most extreme formulation thus far, and seems to be the classic Reidian dualcomponent view-the view that is widely seen as indefensible. ${ }^{10}$ It is worth pushing the general line of thought behind (1) through (3) to its limit, expressed in (3'). The more extreme the view, the more interesting it will be if turns out to be sustainable. I will therefore consider the problem of known illusions relative to $\left(3^{\prime}\right)$.

Consider also the following modern dual-component thesis:

$\left(3^{*}\right) S$ perceptually experiences a as $\mathrm{F}$ only if $\mathrm{S}$ tokens a nonconceptual sensory state which appropriately causes a perceptual seeming that a is $\mathrm{F}^{11}$

I will not address general objections to conceptual content as figuring in perception at all (Smith 2002, Hopp 2011), nor objections to nonconceptual elements of perception (McDowell 1994). Those objections need to be addressed in any full-throated defense of the view, but the goal of this paper is simply to argue that the objections that target the dualcomponent view in particular (as opposed to nonconceptual/conceptual content more generally) are unsuccessful. In replying to the problem of known illusions, I'll argue that (3') deserves another look, and should be considered a live account of perceptual experience in contemporary debates. In particular, modern dual-component theorists should not be so quick to dismiss $\left(3^{\prime}\right)$ in favor of $\left(3^{*}\right)$. I won't marshal any positive arguments against $\left(3^{*}\right)$, but

beliefs can be conscious, occurrent, linguistically expressible mental tokens; if one reserves the term 'judgment' for such states, and uses 'belief' to refer only to unconscious, dispositional, and/or inexpressible mental states, then one should mentally swap out 'belief' for 'judgment' in what follows (though some, e.g., Kriegel 2013, argue that judgment is a mental act rather than a state).

9 I add "appropriately" to rule out deviant causal chains.

${ }^{10}$ It seems to be the one that Smith (2002, chapter 3), for instance, is referring to when he coins the phrase 'dual-component view'.

${ }^{11}$ For simplicity's sake, I construe modern dual-component views here as requiring that perceptual seemings are caused by sensory states. One could certainly hold instead that there are separate, parallel causal routes to the sensory and conceptual components of experience rather than one linear route. Nothing that follows should hang on this. 
if the problem of known illusions doesn't make us reject (3'), then one major motivation for $\left(3^{*}\right)$ has been removed.

\section{\$3-The problem of known illusions}

3.1-Perceptual and central beliefs. As aforementioned, the problem of known illusions casts doubt on (3') as an account of perceptual experience. One can see the woman in the Ames Room as much taller than the man while also knowing, and hence believing, that she isn't. This fact seems at odds with the claim, at the heart of the classical dual-component view, that one's perceptual experience of the woman as larger constitutively involves a belief that represents her as such. The challenge for the dual-component theorist is to construe the perceptual belief in such a way that it could withstand incompatibility with other beliefs, but without stipulating ad hoc properties and mechanisms that vacate the claim that perceptual beliefs are genuine beliefs of any substantive theoretical content.

Any theorist who accepts the existence of beliefs will likely accept the distinction between perceptual beliefs and non-perceptual beliefs formed through conscious inference (call the latter "central" beliefs), simply insofar as she accepts that some beliefs are generated by sensory-perceptual states without conscious inference, and others are not. ${ }^{12}$ Consider the case of Leah, who is looking at a green square and tokening two beliefs, ${ }^{13}$ the belief THAT IS A GREEN SQUARE and the belief TOM HANKS IS OVERRATED. The former, perceptual belief seems to be directly caused by sensory states without any inference, whereas the latter, central belief likely involved rich conscious inference. Leah cannot stop having the perceptual belief token as long as her eyes are open and she is paying attention to what she sees, whereas she could easily stop having the central belief token. If these descriptions of Leah's cognitive situation are accurate, then there is a functional distinction between perceptual and central beliefs-even though they are both genuine beliefs. Perceptual beliefs are formed automatically in that sensory states give rise to them by some causal process that subjects are neither aware of nor voluntarily able to cancel.

Bonjour notes that the phenomenology of perceptual beliefs supports this automaticity claim:

I do not infer that there is a red book on the desk, nor does the belief result from any other sort of deliberative or ratiocinative process, whether explicit or implicit. Rather it simply occurs to me, "strikes me," in a manner which is both involuntary and quite

${ }^{12}$ Compare Lyons's distinction between perceptual and inferential beliefs (2005, 249-252).

${ }^{13}$ By the tokening of a belief, I mean the explicit formation of a token mental representation to which one occurrently stands in the belief relation, understood in psychofunctional terms (Fodor 1978). 
coercive; such a belief is, I will say, cognitively spontaneous. It is cognitive spontaneity which marks the belief as putatively observational[.]

(Bonjour 1985, 117; emphasis his.)

According to Bonjour, the intuitive thing to say about the process of perceptual-belief formation is that the process is noninferential and not something the subject enacts in a voluntary, rational, cancellable way. Classical dual-component theorists can appeal to this intuition and thus claim independent grounds for accepting the automaticity of perceptualbelief formation (hereafter 'AP').

AP is, furthermore, likely going to be an independent commitment of classical dualcomponent theorists. As Reid wrote, for instance, "Perception commands our belief upon its own authority, and disdains to rest its authority upon any reasoning whatsoever" (Reid $1785 / 2000$, 99). Some philosophers may consider perceptual-belief formation to be a matter of drawing inferences from our experiences. ${ }^{14}$ While that might turn out to be true, it doesn't intuitively seem to be true in the typical case. In the typical case, it appears from the firstperson as though we open our eyes and, if there is a tiger before us, we immediately and without any effort or inference come to believe that there is a tiger before us.

AP is further supported by the extensive empirical results that motivate the more general Spinozan thesis of the automaticity of belief formation (Gilbert 1991, Egan 2008, 2011, Mandelbaum 2014, Mandelbaum and Quilty-Dunn forthcoming). In general, there is some empirical reason to think that propositional content tokened in the mind is passively accepted and then serves as a basis for further inferences and decision-making even if subjects sincerely deny such acceptance (see, e.g., Gilbert et al. 1993). These results, together with the more commonsense intuition that our beliefs about our immediate environment are formed in a noninferential, involuntary way, provide independent grounds for accepting AP.

There are also a priori reasons to expect AP to be true (see Mandelbaum and Quilty-Dunn forthcoming). For one thing, it seems likely that a cognitive system that evolved to form beliefs in real time as a way of acting immediately upon one's environment would operate according to AP. If one perceives a tiger, it would be far preferable to automatically (hence immediately, without checking to make sure the belief is rational) form the belief that there's a tiger over there. A system that requires the organism to check whether it really makes sense for there to be a tiger in front of it will be slower, and thus more likely to be devoured by tigers. Cognition evolving out of perception would have done well (though perhaps not

\footnotetext{
${ }^{14}$ See, e.g., Siegel ms - though Siegel's use of "inference" is quite broad and thus may accommodate the relevant intuition.
} 
epistemologically speaking) to simply accept the outputs of perceptual systems for immediate use in reasoning and decision-making.

Even putting (admittedly, weak) evolutionary considerations aside, however, there are more general a priori design considerations that make AP more architecturally plausible than its negation. Suppose Leah has sensory states of the kind that typically lead to beliefs about tigers. How can she come to acquire the belief that there is a tiger in front of her? One possibility is that she sifts through all her beliefs to determine whether or not the proposition that there is a tiger in front of her fits into her stock of beliefs. This possibility doesn't seem architecturally feasible, however. Given the vastness of our conceptual resources, it would be unwieldy to have to check sensory input against all our background beliefs before forming the relevant belief. A much more feasible mental architecture would simply accept whatever is conceptualized, allowing the resultant belief to be used for action and inference without requiring an ungainly epistemic background check. This consideration is similar to the "frame problem" in AI (see Shanahan 2009 for an overview), which has been a cause for despair in computationally modeling central cognition (e.g., Fodor 2000). The frameproblem-like quandary of figuring out which background beliefs are relevant to perceptual input and whether that input properly accords with them is circumvented if perceptual-belief formation is automatic and ignores background beliefs. Otherwise we are at a loss to say how the cognitive system computationally decides which propositions are believed and which aren't. $^{15}$

Now imagine that Leah comes to believe that there is no green square, because she thinks she is hallucinating. Would she immediately lose her perceptual belief? AP provides us with independent theoretical grounds to suspect that the answer is no. As long as the relevant sensory states persist, then given their strong automatic causal dispositions to generate perceptual beliefs, then we have reason to think that the perceptual beliefs will persist as well.

This is particularly so if we assume, as commonsense invites us to, that the process of perceptual-belief formation is noninferential. Consider how background beliefs (viz., in this case, Leah's belief that she is hallucinating) are supposed to mediate the perceptual-belief formation process. In particular, such beliefs are purported to mediate the process in a rational way. Leah's belief that she is hallucinating semantically conflicts with the putative perceptual belief that there is a green square before her, and it's because of this semantic conflict that the former belief supposedly shuts down the production of the latter. If the process of perceptual-belief formation is a form of inference, then we should expect that, qua

15 This doxastic version of the frame problem is separate from the similar problem about which concepts to apply to a given stimulus, which AP doesn't speak to. 
inferential process, it is rationally mediated by background beliefs. But given the assumption that the process is not inferential but "immediate" (Reid 1764/1997, 37) and built into the architecture of the mind, it's not clear why we should think there is any such rational mediation by background beliefs. On the contrary, if the process of perceptual-belief formation is noninferential, we might expect that it isn't rationally mediated by background beliefs, in which case we should not expect the acquisition of contrary background beliefs in known-illusion cases to block the formation of false perceptual beliefs.

3.2-Endorsement. The natural objection to this line of thought is that Leah's behavior, including her speech, would belie the claim that she had a persistent false perceptual belief. For instance, if asked whether there were a green square in front of her, she may answer, "No." In reply, the classical dual-component theorist could appeal to the psychological mechanism of endorsement ('ME'). One often has desires one does not endorse, for whatever reason (Frankfurt 1971), and there are analogous cases for belief, such as cognitive dissonance (Festinger 1957), implicit bias, ${ }^{16}$ and more typical cases of unconscious or unattended beliefs.

In the case of perceptual beliefs, the relevant states are conscious. But that doesn't require that they can't persist without being endorsed. For one thing, it seems possible that implicit (e.g.) racist attitudes might sometimes surface in consciousness without being endorsed by the subject. Consider a person who harbors implicit racist attitudes and finds herself inching away from someone of a different race on the subway and momentarily becomes conscious of this racist belief and its role in her behavior without endorsing it. This sort of case seems perfectly plausible (or at the very least, conceivable), and doesn't require eliminating the relevant belief - if eliminating racist attitudes were that easy, the world would be a vastly better place than it is.

Furthermore, the fact that the content of a perceptual belief is conscious doesn't require that the subject is conscious of the state that has that content as a belief. The claim that the conceptual component of perceptual experience is belief is a theoretical claim, not one that falls right out of introspection. It would be seriously uncharitable to construe the classical dual-component theorist (or indeed, any doxastic theorist) as committed to the claim that perceptual beliefs always appear as such to perceiving subjects. On the contrary, the classical dual-component theorist should hold that subjects simply take themselves to be having an

\footnotetext{
${ }^{16}$ See, e.g., Payne 2001 for a classic implicit racism study, and Mann and Ferguson (2015) for implicit propositional structures; see Mandelbaum forthcoming for defense of the idea that implicit attitudes are unendorsed beliefs. See also Rozin et al 1986, Rozin et al 1990, Gill and Gilbert 1999, and Gilbert 2002, for (controversial) cases of perceptual beliefs that seem to be at odds with all-things-considered background knowledge.
} 
experience that such-and-such is the case. Reid frequently stressed that ordinary people fail even to pull apart the conceptual and nonconceptual components of experience. In that case, he should hardly be read as saying that they will accurately characterize the conceptual component as a belief. Instead, the classical dual-component theory should take introspective concepts to be more coarsely grained. In that case, the fact that in a known-illusion case, the false perceptual belief is part of a conscious experience need not require that the subject represents herself as having contradictory beliefs, nor that the endorsement of the true central belief requires eliminating the perceptual belief or submerging it below the level of consciousness.

The results in support of the Spinozan theory of belief formation also call for such a mechanism to explain why, despite the fact that subjects appear to automatically form false beliefs and draw inferences from them, the very same subjects will deny having those beliefs and explicitly assert their contraries. There is good reason, therefore, to suppose that in addition to merely acquiring a given belief, there is an additional selective mechanism of endorsement that involves attributing the belief to oneself and acquiring a willingness to assert and defend it. ${ }^{17}$ Buckwalter et al. (forthcoming) argue on empirical grounds that even folk psychology makes the distinction between merely having a belief (what they call "thin belief'), and endorsing that belief, in the sense of making an emotional commitment to it and being willing to assert and defend it (what they call "thick belief'). The dual-component theorist could thus say that the central belief is endorsed by the subject and the perceptual belief is not, which accounts for the asymmetry in their functional impacts. We can explain why perceptual beliefs are resistant to revision by appeal to AP, and we can explain why central beliefs in known-illusion cases govern behavior and speech by appeal to ME.

3.3-Are these really beliefs? One might nonetheless continue to object that perceptual beliefs do not act like beliefs, so they are not beliefs. Recall the six distinctive features of belief mentioned above: (i) propositional content, (ii) assertoric force or attitude, (iii) the capacity to serve as a premise in inferences, (iv) linguistic expressibility in creatures capable of linguistic expression, (v) being characteristically linguistically expressed in the form of an assertion, and (vi) being disposed to interact in characteristic ways with desires, emotions,

\footnotetext{
${ }^{17}$ The connection between assertion and self-attribution may be responsible for Moore's Paradox, i.e., the practical irrationality of asserting statements of the form " $p$, but I don't believe that $p$ " (see Rosenthal 2005 for discussion).
} 
action, and memory. ${ }^{18}$ Perceptual beliefs don't seem to occurrently exhibit all of these properties in the same ways in known-illusion cases, so perhaps they are not genuine beliefs.

Four points should suffice to block this objection. First, it is open to the dual-component theorist to say perceptual beliefs act like normal beliefs in normal cases. Right now, for instance, my perceptual belief that there is something white in front of me causes me to infer that there is something not-black in front of me, and (say) causes me to assert, "That is white." If white things made me afraid, then I would become afraid, and if I wanted to avoid white things, then I would avoid it. Perceptual beliefs also act normally in typical cases of illusion. It is only in cases of known illusion, which is an unusual and particular type of situation, that perceptual beliefs act weirdly.

Second, beliefs, like all functionally specified mental states, are specified in terms of what functions they are disposed to fulfill, not which ones they actually do fulfill. All dispositions can be muted. The fact that a state does not enact the causal powers that are typical of states of a certain type does not, therefore, entail that the state is not of that type. This fact is especially salient when the failure to enact these causal powers arises in special and unusual cases, and when there are independently posited mechanisms that account for the failure. Consider the following truism of both folk psychology and the belief-desire psychology that drives much of cognitive science: If $S$ believes that if $\mathrm{p}$ then $\mathrm{q}$ and desires that $\mathrm{q}$, then $S$ will act in such ways as to bring it about that $\mathrm{p}$. This "truism," as stated, must be either false or only be true ceteris paribus. One can have a desire to die and believe that if one jumps off the nearest building then one will die, but not actually jump off the nearest building. The reason for this is that the rest is not equal in such cases. There may be intervening contrary desires, or relevant affective responses, or one may be paralyzed, or there may be other intervening factors. There are independently posited mechanisms (varying case-by-case) that explain why a state does not occurrently fulfill its characteristic functions in a particular situation. The ubiquity of such intervening factors in the massively complex cognitive lives of human beings

\footnotetext{
${ }^{18}$ One might argue that beliefs constitutively operate in accordance with certain norms, such as general coherence. This objection confuses the role of norms in governing causal processes. It might be constitutive of beliefs that there are certain epistemic norms governing them, but that does not entail that our doxastic practices always will—or even normally do-conform to those normative constraints. Likewise, it might be constitutive of human action that it is governed by ethical norms, but that should be compatible with the possibility that human action is often, usually, or even always immoral. There must be an independent descriptive characterization of human action for this possibility to be coherent, and the same must be true in the case of belief.
} 
is why functional roles are dispositional, and depend on the rest being equal, which it often is not. I'll frequently return to this point below.

Third, it is an open question to what extent the typical functional role of perceptual belief actually fails to be occurrent in known-illusion cases. For example, one characteristic role is exciting certain emotions, and a perceptual belief that there is a tiger before you may elicit a fear response even though you know that belief to be false-if you're in a realistic virtual reality setup, for example, or knowingly having a nightmare, or, more controversially, watching a film (Kivy 2012, Quilty-Dunn forthcoming). Many theorists will deny that the relevant state is a belief, but from the perspective of a classical dual-component theorist, it seems legitimate to appeal to the characteristically doxastic emotional impact of the conceptual component of perceptual experience to preserve the claim that it is doxastic. ${ }^{19}$ With respect to inferential promiscuity, though it certainly seems subjectively that we don't draw inferences that take knowingly false propositions as premises, the question is an empirical one. Gilbert et al. (1993) provide evidence that subjects under load draw inferences from linguistically presented propositions that they are told are false, and the same may happen in the perceptual case, though this has apparently not been tested. ${ }^{20}$ And finally, though we will not knowingly assent to the sentence "There is a triangle in front of me" in a known illusion of a triangle (such as the Kanisza triangle illusion), we could test reaction

${ }^{19}$ Gendler (2008) argues for the existence of a sui generis type of mental state, which she calls "alief," that is responsible for such cases. I put aliefs aside here for two reasons. I think it is quite doubtful that aliefs exist, given that the relevant phenomena can likely be explained by appeal to irrationally formed beliefs or activated associative links (see Mandelbaum 2013). Even if they do exist, however, Gendler suggests that the representations that figure in them are bound only associatively, not predicatively (see, e.g., Gendler 2008, 648). The conceptual components on any extant dual-component theory involve predication, and hence propositional content. This is important for many reasons (including epistemological ones), but most basically to provide accuracy conditions, which are a sine qua non for perceptual representation. Since aliefs don't have propositional contents or determine accuracy conditions, they aren't a candidate for the conceptual component of perceptual experience. One might propose a view on which aliefs are propositional, but that reading doesn't distinguish them from seemings or beliefs, in which case they don't add to the present discussion.

${ }^{20}$ Language comprehension certainly seems perceptual, particularly given the commitment of all dual-component theories that cognitive states can be constituents of perceptual experience. In that case, Gilbert et al.'s results might be argued to show a case of inference from false perceptual beliefs. But since linguistic processing is in many ways quite unique, I leave this possibility aside. 
times on judging that sentence and related sentences to be true or false; a higher reaction time in judging the known illusory content false would suggest that subjects unknowingly believe the proposition and must overcome that persistent false perceptual belief, thus slowing down their judgment of its falsity compared to subjects who aren't under that perceptual illusion. ${ }^{21}$

And, finally, there are independently posited mechanisms that explain why perceptual beliefs fail to fulfill all the functions that are dispositionally characteristic of belief in known-illusion cases: AP, which explains inferential resistance, and $\mathrm{ME}$, which explains why the incompatible central belief, and not the errant perceptual belief, governs speech and behavior. Since AP and ME are both independently grounded, the dual-component theorist can explain known-illusion cases while also maintaining that perceptual beliefs are genuine beliefs. $^{22}$

According to the view articulated here, the conceptual components of perceptual experience are the very same sorts of psychofunctional states that are posited in belief-desire psychology: the states that are disposed to serve as premises in inferences and interact in typical ways with language, desires, emotions, memory, and action. They are specific sorts of beliefs with a specific type of content and connection to sensory states, but this does not necessarily make them distinct kinds of propositional attitudes. There are many kinds of beliefs, including but not limited to: introspective beliefs, mnemonic (memory-based) beliefs, beliefs based on explicit inferences, delusory beliefs, implicit beliefs, strong beliefs, weak beliefs, and perceptual beliefs. These states all differ either in virtue of their content, their credence, or their causal/architectural position, but are the same in that they have the ceteris paribus functional role specified above- they are all beliefs.

The mere fact that perceptual beliefs, on the dual-component view, fail to fulfill their characteristic (but ceteris paribus) functions in certain strange cases is not enough to conclude that they are not genuine beliefs. All beliefs (indeed, all functionally individuated mental states) will fail to fulfill their characteristic functions in strange cases, and there are independent explanations offered above as to why perceptual beliefs fail to fulfill their typical roles in the strange cases of known illusions.

More conjecturally, there are arguably reasons to think beliefs can be compartmentalized or "fragmented" to some considerable degree, and perceptual beliefs are likely no exception. ${ }^{23}$ In

\footnotetext{
${ }^{21}$ I hope to implement an experiment along these lines in the future.

${ }^{22}$ See also Armstrong 2002 and Byrne 2009, 2012.

${ }^{23}$ See Lewis 1982, Egan 2008, 2011, Mandelbaum forthcoming.
} 
cases of fragmentation, beliefs occur in "fragments," or isolated networks, without interacting in one giant "web of belief." The fact that a belief in one fragment can't interact inferentially with a belief in another fragment doesn't seem to threaten the status of either state as a belief; it is a contingent fact about mental architecture rather than an internal feature of the propositional attitude that is responsible for the lack of canonically belief-like causal interaction. Even if the fragmentation thesis is false, the mere coherence of the thesis shows that a belief can still be a belief despite its causal impact being altered by mental architecture.

3.4-Perceptual beliefs vs. perceptual seemings. As mentioned at the outset, some modern dualcomponent theorists argue that the known-illusion objection gives us good reason to suppose that there are nondoxastic but conceptual/propositional states like "seemings" (Brogaard 2014, Reiland 2014) involved in perceptual experience. These putative states are sui generis types of propositional attitudes that make things seem a certain way to the subject without involving belief. One may argue that perceptual beliefs as construed on the version of the classical view articulated here are simply the seemings advocated by modern theorists, while central beliefs are actually beliefs. ${ }^{24} \mathrm{I}$ will therefore try to clarify the difference between seemings and perceptual beliefs to better understand this difference between classical and modern dual-component views.

Beliefs are affirmative or assertoric in that having a belief involves holding its content to be true. If seemings don't have that property, then that's sufficient for them to be distinct attitudes. But let's assume that seemings, like beliefs, have an assertoric attitude or force. After all, the fact that not just the content of an experience but the experience itself can be accurate or inaccurate seems to require that it have an assertoric attitude; contrast nonassertoric states like desires, which have contents with accuracy conditions but are not themselves accurate or inaccurate (Siegel 2010, 33). One difference between them might be that seemings do not function directly as premises in inferences - or at least not in inferences the conclusions of which are beliefs - and/or that seemings do not stand in the same functional relations to language, desire, emotions, memory, and action as beliefs. Suppose that a person believes that if $p$ then $q$; if they also believe that $p$, then they can directly infer that $q$ without the intermediation of any other intentional states. ${ }^{25}$ Presumably a seeming that $p$, since it is not a belief that $p$, cannot interact directly with the belief that if $p$ then $q$ to produce an inference to the belief that $q$. Thus perhaps the distinction between the modern

${ }^{24}$ Thanks to the editors for raising this point.

${ }^{25}$ This abstracts away from the possibility that inference involves an additional intentional state like an intuition (Chudnoff 2013), which is not relevant to the distinction between belief and seemings. 
view and the classical view consists partially in the fact that the latter view has it that the conceptual component of perceptual experience can interact directly with conditional beliefs to produce a modus ponens inference the conclusion of which is another belief.

Or suppose that a person forms the perceptual belief THAT IS AN APPLE and desires to eat an apple; they are thus directly disposed to grab the apple. Presumably the seeming THAT IS AN APPLE could not interact directly with desire to produce action in this way. The distinction between the two views, therefore, may also consist partially in the fact that, on the classical view, the conceptual component of perceptual experience can interact directly with desires to produce actions. Direct inferential interaction with other beliefs and with desires is a (perhaps the) psychofunctional hallmark of beliefs. If seemings are psychofunctionally distinct attitudes, then they will not exhibit all the psychofunctional hallmarks of beliefs. If that's correct, and if seemings cannot function as direct inputs in these ways, then modern views should predict the construction of an additional representation in order to trigger doxastic events like modus ponens inferences and belief-desire pairings, which could in principle be tested. ${ }^{26}$

One might object that a belief can only trigger doxastic events such as inferences if endorsed by the subject. It's not a necessary assumption of classical dual-component views that inferences require endorsement of the beliefs that figure in them. In fact, there are empirical reasons to think that many inferences occur unconsciously and even involve beliefs that explicitly contradict beliefs the subject endorses (Quilty-Dunn and Mandelbaum ms). Consider the kinds of transitions involved in cases of cognitive dissonance (Festinger 1957), such as effort justification: a person exerts a great amount of effort or endures unpleasant experiences to achieve some goal, such as joining a group (think of hazing rituals in fraternities or harsh military training), and ends up with a more positive judgment of the

${ }^{26}$ Modern dual-component views appear especially committed to the claim that seemings require the construction of an additional representation when one considers the putative epistemological function of seemings on (at least some of) these views. The perceptual seeming that $\mathrm{p}$ is the source of prima facie justification for the perceptual belief that $\mathrm{p}$ (Tucker 2010, Reiland forthcoming), in line with epistemological dogmatism (Prior 2000) or phenomenal conservatism (Huemer 2007). In that case, it would appear that one won't be in a position to draw doxastic inferences from a perceptual seeming that $\mathrm{p}$ (e.g., pairing with the belief that if $\mathrm{p}$ then $\mathrm{q}$ to make a modus ponens transition to the belief that $\mathrm{q}$ ) without forming the belief that $\mathrm{p}$. If on the other hand seemings trigger such inferences directly, and thus can act epistemically just like the belief that $\mathrm{p}$ without forming the belief that $\mathrm{p}$, their epistemological function in justifying beliefs with type-identical contents seems to evaporate. None of these points apply to Lyons's view, discussed below. 
group because of that fact (Aronson and Mills 1959). Consciously, the person thinks she is forming a rational and objective evaluation that the group she has joined is terrific, but the sensitivity of such judgments to the harshness of the entrance procedure suggests that she performs an inference along the following lines:

(P1) If the group weren't awesome, then I would be stupid for undergoing this unpleasant experience.

(P2) I'm not stupid!

(C) The group is awesome.

For that explanation to work, this modus tollens inference must be able to operate without the subject endorsing it or its premises. Though the subject may in fact endorse each belief if asked, surely her endorsements don't figure in the inferential transition, given how vehemently subjects in these cases would deny performing the inference or consciously thinking P1 or P2 during initiation at all.

There is more recent evidence that deductive inferences are performed automatically (Handley et al. 2011; also see Braine and O’Brien 1998 for a compendium of results in the "mental logic" research program) and unconsciously (Reverberi et al. 2012). This evidence suggests that inferential promiscuity is actualized independently of whether the subject knows about or endorses the relevant beliefs (see Quilty-Dunn and Mandelbaum ms for further discussion). The evidence allows the classical dual-component theorist to claim that perceptual beliefs can be directly inferentially promiscuous without requiring endorsement. ${ }^{27}$ If seemings are really psychofunctionally distinct types of propositional attitudes, then they are presumably incapable of fulfilling this function (see $\mathrm{n} 26$ ). Herein lies a core psychofunctional difference between the two types of states.

The core of the difference between classical and modern views of the conceptual component of perceptual experience is that the distinction between perceptual beliefs and central beliefs is not a distinction between types of propositional attitudes, which the distinction between seemings and beliefs purports to be. The difference between perceptual and central beliefs is, on the classical dual-component theory, an extrinsic relational difference that is determined entirely by architectural factors. The classical dual-component theorist thus claims that such extrinsic architectural factors do not require positing distinct types of propositional attitudes. For instance, suppose Freudian psychoanalytic theory is right that human beings have

\footnotetext{
${ }^{27} \mathrm{NB}$ : It's still open to the classical dual-component theorist to say that the presence of a contrary belief endorsed by the subject will block or at least limit the inferential promiscuity of the unendorsed belief. The question is entirely empirical.
} 
repressed desires. The distinction between repressed and unrepressed desires is a theoretically important distinction, but it is not obviously a distinction between types of propositional attitudes; rather, it is a distinction between desires, instances of the same propositionalattitude type, that is due to extrinsic architectural factors, viz., the fact that one is repressed and the other isn't. The occurrent functional properties of a desire become very different once it is repressed, but it is part of the theory that a desire can preserve type-identity qua desire across such architectural borders. On such a theory, the fact that repressed and unrepressed desires are the same type of propositional attitude is grounded by the truth of certain counterfactuals, such as, If desire $A$ were not repressed, it would act just like unrepressed desire $B$. In that case there is no explanatory need to posit distinct types of attitudes, since the relevant behavioral differences are entirely explained by the extrinsic architectural factors, holding the attitude-type fixed.

This situation is similar to the case of perceptual and central beliefs. The fact that perceptual and central beliefs are the same type of attitude is grounded by the truth of counterfactuals such as, If perceptual belief $P$ were to occur in normal circumstances (i.e., outside the context of known illusions), $P$ would perform the functions that a normal belief performs in normal circumstances. If such counterfactuals are true, there is no explanatory purchase gained by taking perceptual beliefs to be distinct types of attitudes, since the behavioral differences are fully explained by facts about mental architecture while holding the attitude type fixed. Indeed, since perceptual beliefs almost always do occur outside the context of known illusions and exhibit the normal functional properties of beliefs, classical theories argue that we don't need to take them to be a sui generis type of propositional attitude. To use an example in the other direction, it is hardly controversial that the belief that $p$ and the desire that $p$ are genuinely different attitudes; furthermore, the difference does not reduce to architectural factors or differences in content but rather requires the subject to take a different attitude toward $p$. Thus where we find a difference that can't be explained away by architectural or other extrinsic factors, we posit distinct types of attitudes. If it's right that the difference between perceptual and central beliefs does reduce to such factors, that's all the more reason to think they are the same type of attitude.

The fundamental difference between the classical view and the modern view is that the latter quantifies over an additional type of propositional attitude, while the former appeals instead to independently motivated explanatory apparatuses concerning mental architecture and the psychological mechanism of endorsement. Presumably the seemings view does not support counterfactuals such as, If seeming $S$ were to occur outside the context of known illusions, it would fulfill the functions that a normal belief exhibits (though see the discussion of Lyons below). Thus the classical view and the modern view are crucially different in their 
theoretical commitments. While seemings are of their own sui generis type of propositional attitude, perceptual beliefs are merely one among the many different types of beliefs.

Some modern theorists may grant that the difference between seemings and beliefs supervenes entirely on the kinds of factors appealed to in favor of the classical theory above. In that case, it would not be clear that the classical and modern views are really at odds except insofar as whether they take different architectural factors to be sufficient to generate distinct attitude types. Perhaps such a modern theorist would appeal to the different epistemic roles played by the relevant types of states - this would fit with the tendency of some modern theorists to focus on the special role of seemings in providing evidence (Tucker 2010, Reiland forthcoming). The considerations above give us some reason to distinguish beliefs from seemings considered from a purely descriptive point of view, but perhaps the best way of interpreting certain modern theories (though not, e.g., Brogaard 2014) is as making a purely normative twist on classical views rather than as delineating separate psychological kinds. In that case, we can distinguish between descriptive modern views and normative modern views, with only the former being incompatible with the classical view.

3.5-Lyons and counterfactual functional role. According to Lyons (2005, 2009), the change in occurrent functional role in typical and known-illusion cases suggests a difference in attitude: belief in the typical case and a seeming-like state in the known-illusion case (see, e.g., 2005, 242-243). Since both classical and modern views generally claim that the very same type of attitude is involved in typical and known-illusion cases, Lyons's view appears to straddle the line between classical and modern views. Lyons's reason for defending this view is that propositional attitudes are individuated by their functional roles, and once a state fails to fulfill characteristic functions, it can thereby become a different type of attitude while remaining the same token mental state.

Lyons's argument seems to rest on an equivocation with respect to the way in which functional properties determine the type-identity of mental states. He writes of the stereotypical functional properties of belief (e.g., figuring in inferences) that when a representation "has this causal role, it is a belief; when it doesn't, it is a mere percept" (2009, 71). The notion of causal/functional role is, crucially, a ceteris paribus (and hence counterfactual-supporting) notion (see, e.g., Fodor 1978, Loar 1981, Aydede 2005). A belief that there is a beer in the refrigerator has the functional role of interacting with the desire for beer to cause an intention to walk to the refrigerator. Nonetheless, that interaction might not occur if one has a desire to finish writing a paper and a belief that drinking beer will interfere with the writing process. The initial belief and desire are no less a belief and desire in this case then they would be if their functional roles were actualized. The functional role that is constitutive of being a belief contains ceteris paribus clauses that can be violated by many 
factors, especially including other mental states and processes. In cases like the one just described, the initial states maintain type-identity due to the truth of certain counterfactuals, such as:

$\mathrm{C}_{1}$ : If the intervening beliefs and desires hadn't occurred, then the person would have walked to the refrigerator.

Lyons's argument appears to conflate the occurrent functional properties of a mental token with the ceteris paribus, counterfactual-supporting functional role that makes it the type of state it is. It's crucial for the functionalist representational theory of mind that this conflation not be made. The point of positing representations is to explain why a certain mentalbehavioral function is occurrently fulfilled (e.g., why the person walks to the refrigerator, or why they intend to do so). If the representation is type-individuated only by its occurrent functions, then such explanations become trivial, dormitive-virtue ${ }^{28}$ explanations: a function is occurrently performed because of a state occurrently performs that function. The introduction of counterfactuals saves functionalist representational explanations from vacuity by extending the type-individuation of representations beyond the functions that are actually performed to those they perform counterfactually. Since a functionally individuated statetype is independently characterizable whether or not a token of it actually fulfills a certain function on a given occasion, the positing of a token of that type amounts to more than the vacuous claim that something fulfills the occurrently observed function on that occasion. Thus the functionalist representational theory of mind requires a sharp distinction between the actual functions performed by a token mental state and the ceteris paribus, counterfactual-supporting functional role that makes it a token of a given type.

If Lyons's argument is not making this conflation, then it must depend on the premise that the conceptual components of experience lose not only their occurrent causal influence but even the disposition to exhibit that causal influence. It is common ground between Lyons and the classical dual-component theorist that the conceptual components of experience are beliefs in typical cases, and that in known-illusion cases they don't occurrently fulfill all the characteristic functions of beliefs. For Lyons's conclusion to be warranted, there would have to be reason to think that the conceptual components also fail even to counterfactually fulfill the characteristic functions of beliefs. If known-illusion cases work as described above, then we can spell out the relevant counterfactual:

\footnotetext{
${ }^{28}$ Moliere famously mentioned the vacuity of explaining the fact that opium makes people sleep by saying it has a dormitive virtue, which is empty because it restates the explanandum rather than explaining it.
} 
$\mathrm{C}_{2}$ : If there weren't a contrary central belief endorsed by the subject, then the perceptual belief would fulfill the functions characteristic of a belief.

If $\mathrm{C}_{2}$ is true, then it seems to secure the metaphysical status of the perceptual belief qua belief just as the truth of $\mathrm{C}_{1}$ secures the metaphysical status of the blocked belief and desire as such. Lyons claims that being a belief is "not an essential property of a mental state but one that the state can gain or lose over time" $(2005,243)$. If we assume that belief is a relation to a mental representation (Fodor 1978), then it does seem conceivable that we could come to bear a different relation to that mental representation without its losing its token-identity. Lyons's claim thus seems to be correct. It's not clear, unfortunately, how to tell when we cease to stand in the belief relation to a token mental representation. The reason it's difficult to tell is that losing the belief relation cannot consist merely in the representation's failing to occurrently fulfill characteristic functions of belief; it must be that it loses the functional role understood in ceteris paribus, counterfactual-supporting terms. Thus counterfactuals like $\mathrm{C}_{1}$ must no longer be true of a representation for it to no longer be "in the belief box" (Schiffer 1981). An additional constraint must be that those counterfactuals aren't trivial, like $\mathrm{C}_{3}$ :

$\mathrm{C}_{3}$ : If the mental representation were altered in such a way to fulfill the functions characteristic of a belief, then it would be a belief.

The burden on Lyons to refute the classical dual-component view articulated in this paper would be to show that $C_{2}$ is really a trivial counterfactual like $C_{3}$. Prima facie, at least, $C_{2}$ looks more like a substantive counterfactual like $\mathrm{C}_{1}$ and seems to specify non-trivial circumstances in which the representation would act like a normal belief, circumstances that are just like those in $\mathrm{C}_{1}$ (viz., the contingent presence of mental states and processes that block the functioning of the relevant state).

One may object that while there may be intervening states and processes that limit a state's causal powers without changing its psychofunctional type, there is something special about the case of known illusions. In particular, the perceptual belief that $\mathrm{p}$ has its powers limited by (inter alia) the belief that not-p. Perhaps this case is different in some way from ordinary cases of mental dispositions being blocked by other mental states; perhaps the existence of the contrary belief changes the functional role of the conceptual component of the experience in such a way as to make it fail to be a belief. This suggestion is implausible, however, for the simple reason that there can be contradictory beliefs. One may have an implicit homophobic belief whose dispositions are blocked by a contrary conscious egalitarian belief; the former belief doesn't fail to be a belief on those grounds alone. The homophobic belief may fail to occurrently exhibit certain functional properties such as inferential promiscuity, but it doesn't follow that it also loses even the disposition to exhibit 
those properties. Similarly, while a perceptual belief in a known-illusion case may not actually trigger inferences, it needs to be shown that it also loses the disposition to trigger inferences. The existence of a contrary central belief seems to operate like an ordinary psychofunctional defeater: if it is present, the blocked state retains its dispositions but fails to actualize them, and if it is removed, the blocked state will be able to actualize its dispositions. There is no reason to think that the existence of a contrary central belief changes the ceteris paribus, counterfactual-supporting functional role of a perceptual belief simply because it limits its occurrent causal interactions.

3.6 - Folk psychology. Finally, one might raise the objection that the classical dual-component theory's response to the problem of known illusions conflicts with folk psychology. The general ceteris paribus functional role attributed to beliefs in this paper, however, seems (to me) perfectly commonsense, or at least is not obviously incompatible with the folkpsychological notion of belief. A theory can posit the same kind of beliefs posited by folk psychology while nonetheless going beyond or contradicting folk psychology in judging whether a certain case involves beliefs. As Fodor wrote in the context of defending the general contours of commonsense belief-desire psychology, "A lot of what common sense believes about the attitudes must surely be false (a lot of what common sense believes about anything must surely be false)" $(1987,15)$. Perhaps scientific psychology has uncovered that we house racist beliefs we don't know about; surely the fact that that empirical claim is not contained in folk psychology does not undermine the fact that scientific psychology concerns beliefs, and quantifies over them in its explanation of racist behavior. Likewise, the notion of belief that perceptual beliefs satisfy may accord with the general notion of belief from folk psychology even though folk psychology wouldn't attribute persistent false beliefs in knownillusion cases. Cognitive science can preserve the folk-psychological kind belief without preserving all folk intuitions about which cases do and don't involve belief.

Furthermore, claims about the contents of these folk intuitions are empirically testable. And as it turns out, ordinary speakers of English attribute beliefs even when they do not occurrently exhibit standard functional properties, such as in cases of persistent delusions that conflict with the deluded person's behavior (Rose et al. 2014). This suggests that folk psychology does allow preservation of attitude-type despite lack of occurrent fulfillment of characteristic functions. And as aforementioned, Buckwalter et al. (forthcoming) use data such as this to argue that the folk even draw the distinction between endorsed and unendorsed beliefs. A blanket appeal to folk psychology against the classical dual-component view therefore appears to oversimplify the content of folk psychology. 


\section{$\$ 4-$ Conclusion}

The dual-component theory, in any of its forms, is a substantive and explanatorily powerful account of human perceptual experience. The classical form of the view, according to which the conceptual components of experience are beliefs, has been largely put aside. The problem of known illusions has been a primary reason for putting aside the classical dual-component view. I've argued that the classical view has the resources to answer this challenge without giving up its core claims. The classical dual-component theory—or indeed any sort of dualcomponent theory_faces other objections not explored here, some of which may be fatal. Nonetheless, the classical dual-component theory shouldn't be rejected simply because of the problem of known illusions. Philosophers of perception in general, and modern dualcomponent theorists in particular, should take the classical dual-component theory seriously. ${ }^{29}$

${ }^{29}$ I'm grateful to Jake Berger, Simon Brown, Becko Copenhaver, Ryan DeChant, Nemira Gasiunas, Grace Helton, Zoe Jenkin, Alex Kiefer, Eric Mandelbaum, Ben Phillips, Jesse Prinz, David Rosenthal, and Henry Shevlin for comments on earlier drafts. Special thanks to Jack Lyons and Indrek Reiland for many helpful comments. 


\section{Bibliography}

Armstrong, D. M. (2002). A Materialist Theory of Mind: Revised Edition. New York: Routledge.

Aronson, E., and Mills, J. (1959). The effect of severity of initiation on liking for a group. Journal of Abnormal and Social Psychology 59, 177-181.

Aydede, M. (2005). Computation and functionalism: Syntactic theory of mind revisited. In Turkish Studies in the History and Philosophy of Science, eds. G. Irzik and G. Güzeldere (Dordrecht: Springer), 177-204.

Bengson, J., Grube, E., and Korman, D. (2011). A new framework for conceptualism. Noûs 45(1), 167-189.

Braine, M. D. S., and O'Brien, D. P., eds. (1998). Mental logic. Mahwah, NJ: Erlbaum.

Brogaard, B. (2014). Seeing as a non-experiential mental state: The case from synesthesia and visual imagery. In Consciousness Inside and Out: Phenomenology, Neuroscience, and the Nature of Experience, ed. R. Brown, 377-394.

Buckwalter, W., Rose, D., and Turri, J. (Forthcoming). Belief through thick and thin. Noûs.

Burge, T. (2009). Five theses on de re states and attitudes. In The Philosophy of David Kaplan, eds. J. Almog and P. Leonardi (Oxford: OUP), 246-324.f

---. (2010). The Origins of Objectivity. Oxford: OUP.

---. (2014). Reply to Rescorla and Peacocke: Perceptual content in light of perceptual constancies and biological constraints. Philosophy and Phenomenological Research 88(2), 485-501.

Byrne, A. (2005). Perception and conceptual content. In Contemporary Debates in Epistemology, eds. M. Steup and E. Sosa (Malden, MA: Blackwell), 231-250.

---. (2009). Experience and content. Philosophical Quarterly 59(236), 429-451.

---. (2012). Knowing what I see. In Introspection and Consciousness, eds. D. Smithies and D. Stoljar (Oxford: OUP), 183-210.

Carruthers, P. (1996). Language, Thought and Consciousness: An Essay in Philosophical Psychology. Cambridge: Cambridge University Press.

Chalmers, D. (2004). The representational character of experience. In The Future for Philosophy, ed. B. Leiter (Oxford: OUP), 153-181.

---. (2006). Perception and the fall from Eden. In Perceptual Experience, eds. T. Gendler and J. Hawthorne (Oxford: OUP), 49-125.

Chisholm, R. (1957). Perceiving: A philosophical study. Ithaca, New York: Cornell University Press.

Chudnoff, E. (2014). The rational roles of intuitions. In Intuitions, ed. A. Booth and D. Rowbottom (Oxford: OUP), 9-35.

Coates, P. (2007). The Metaphysics of Perception: Wilfrid Sellars, Critical Realism and the Nature of Experience. New York, NY: Routledge.

Dretske, F. (1981). Knowledge and the Flow of Information. Cambridge, MA: MIT Press.

Egan, A. (2008). Seeing and believing: Perception, belief formation and the divided mind. Philosophical Studies 140(1), 47-63. 
---. (2011). Comments on Gendler's, "The epistemic costs of implicit bias." Philosophical Studies 156(1), 65-79.

Evans, G. (1982). The Varieties of Reference. Oxford: OUP.

Festinger, L. (1957). A Theory of Cognitive Dissonance. Stanford, CA: Stanford University Press.

Fodor, J. (1978). Propositional attitudes. The Monist 61(4), 501-523.

---. (1987). Psychosemantics: The Problem of Meaning in the Philosophy of Mind. Cambridge, MA: MIT Press.

---. (2000). The Mind Doesn't Work That Way. Cambridge, MA: MIT Press.

---. (2007). The revenge of the given. In Contemporary Debates in Philosophy of Mind, eds. B. McLaughlin and J. Cohen (Oxford: Blackwell), 105-116.

Frankfurt, H. (1971). Freedom of the will and the concept of a person. Journal of Philosophy 68(1), 5-20.

Gendler, T. S. (2008). Alief and belief. Journal of Philosophy 105(10), 634-663.

Gilbert, D. (1991). How mental systems believe. American Psychologist 46(2), 107-119.

---. (2002). Inferential correction. In Heuristics and Biases: The Psychology of Intuitive Judgment, eds. T. Gilovich, D. Griffin, and D. Kahneman (Cambridge: Cambridge University Press), 167-184.

Gilbert, D., Tafarodi, R., and Malone, P. (1993). You can't not believe everything you read. Journal of Personality and Social Psychology 65(2), 221-233.

Gill, M. and Gilbert, D. (1999, unpublished). Sequential operations in self-perception. Cited in Gilbert 2002, 177.

Grice, H. P. (1961). The causal theory of perception. Proceedings of the Aristotelian Society 35, $121-152$.

Handley, S., Newstead, S., and Trippas, D. (2011). Logic, beliefs, and instruction: A test of the default interventionist account of belief bias. Journal of Experimental Psychology: Learning, Memory, and Cognition 37(1), 28-43

Heck, R. (2000). Nonconceptual content and the "space of reasons." The Philosophical Review 109(4), 483-523.

Hopp, W. (2011). Perception and Knowledge. Cambridge: Cambridge University Press.

Huemer, M. (2007). Compassionate phenomenal conservatism. Philosophy and Phenomenological Research 74(1), 30-55.

Kriegel, U. (2013). Entertaining as a propositional attitude: A nonreductive characterization. American Philosophical Quarterly 50(1), 1-22.

Lewis, D. (1982). Logic for equivocators. Nồs 16(3), 431-441.

Loar, B. (1981). Mind and Meaning. Cambridge: Cambridge University Press.

Lycan, W. (1986). Tacit belief. In Belief: Form, Content, and Function, ed. R. J. Bogden (Oxford: OUP), 61-82.

Lyons, J. (2005). Perceptual belief and nonexperiential looks. Philosophical Perspectives 19(1), 237-256

---. (2009). Perception and Basic Beliefs: Zombies, Modules, and the Problem of the External World. Oxford: OUP. 
Mandelbaum, E. (2013). Against alief. Philosophical Studies 164(1), 197-211.

---. (2014). Thinking is believing. Inquiry 57(1), 55-96.

---. (forthcoming). Attitude, inference, association: On the propositional structure of implicit bias. Noûs.

Mandelbaum, E. and Quilty-Dunn, J. (Forthcoming). Believing without reason, or Why liberals shouldn't watch Fox News. Harvard Review of Philosophy.

Mandik, P. (2012). Color-consciousness conceptualism. Consciousness and Cognition 21, 617-631.

Mann, T. and Ferguson, M. (2015). Can we undo our first impressions? The role of reinterpretation in reversing implicit evaluations. Journal of Personality and Social Psychology 108(6), 823-849.

McDowell, J. (1994) Mind and World. Cambridge, MA: Harvard University Press.

McLaughlin, B. (1984). Perception, causation, and supervenience. Midwest Studies in Philosophy 9, 569-591.

Payne, K. (2001). Prejudice and perception: The role of automatic and controlled processes in misperceiving a weapon. Journal of Personality and Social Psychology 81, 181-192.

Peacocke, C. (1992). A Study of Concepts. Cambridge, MA: MIT Press.

---. (2001). Does perception have a nonconceptual content? The Journal of Philosophy 98(5), 239-264.

Pryor, J. (2000). The skeptic and the dogmatist. Nô̂s 34(4), 517-549.

Quilty-Dunn, J. (forthcoming). Believing our eyes: The role of false belief in the experience of cinema. British Journal of Aesthetics.

Quilty-Dunn, J. and Mandelbaum, E. (ms). Inferential transitions.

Reid, T. (1764). Inquiry into the Human Mind on the Principles of Common Sense. Ed. D. Brookes, 1997. University Park, PA: Pennsylvania State University Press.

---. (1785). Essays on the Intellectual Powers of Man. Ed. D. Brookes, 2000. University Park, PA: Pennsylvania State University Press.

Reiland, I. (2014). On experiencing high-level properties. American Philosophical Quarterly $51,177-187$.

---. (forthcoming). Experience, seemings, and evidence. Pacific Philosophical Quarterly.

Reverberi, C., Pischedda, D., Burigo, M., and Cherubini, P. (2012). Deduction without awareness. Acta Psychologica 139, 244-253.

Rose, D., Buckwalter, W., and Turri, J. (2014). When words speak louder than actions: Delusion, belief, and the power of assertion. Australasian Journal of Philosophy 92(4), 683-700.

Rosenthal, D. (2005). Consciousness and Mind. Oxford: Oxford University Press.

---. (2010). How to think about mental qualities. Philosophical Issues 20, 368-393.

Rozin, P., Markwith, M., and Ross, B. (1990). The sympathetic magical law of similarity, nominal realism and neglect of negatives in response to negative labels. Psychological Science 1(6): 383-384. 
Rozin, P., Millman, L., and Nemeroff, C. (1986). Operations of the laws of sympathetic magic in disgust and other domains. Journal of Personality and Social Psychology 50(4): 703-712.

Schiffer, S. (1981). Truth and the theory of content. In Meaning and Understanding, eds. H. Parret and J. Bouveresse (Berlin: Walter de Gruyter), 204-222.

Schwitzgebel, E. (2010). Acting contrary to our professed beliefs, or the gulf between occurrent judgment and dispositional belief. Pacific Philosophical Quarterly 91, 531553.

Searle, J. R. (1983). Intentionality: An Essay in the Philosophy of Mind. Cambridge: Cambridge University Press.

Sellars, W. (1956). Empiricism and the Philosophy of Mind. New edition, 1997. Cambridge, MA: Harvard University Press.

Siegel, S. (2010). The Contents of Visual Experience. Oxford: OUP.

---. (ms). The Rationality of Perception.

Smith, A. D. (2001). Perception and belief. Philosophy and Phenomenological Research 62(2), 283-309.

---. (2002). The Problem of Perception. First Indian edition, 2005. New Delhi: Motilal Barnasidass.

Tucker, C. (2010). Why open-minded people should endorse dogmatism. Philosophical Perspectives 24, 529-545.

Tye, M. (1995). Ten Problems of Consciousness: A Representational Theory of the Phenomenal Mind. Cambridge, MA: MIT Press. 